\title{
Patient-reported areas for quality improvement in general practice:
}

\author{
a cross-sectional survey
}

\begin{abstract}
Background

GPs are often a patient's first point of contact with the health system. The increasing demands imposed on GPs may have an impact on the quality of care delivered. Patients are well placed to make judgements about aspects of care that need to be improved.

\section{Aim}

To determine whether general practice patients perceive that the care they receive is 'patient-centred' across eight domains of care, and to determine the association between sociodemographic, GP and practice characteristics, detection of preventive health contact with the healthcare system, making them ideal in providing care that encompasses health promotion, illness prevention, treatment and care of the sick, community development, and advocacy and rehabilitation. ${ }^{1}$ GPs have access to a large proportion of the population; approximately $83 \%$ of Australians visited a GP in 2010. ${ }^{1}$ In the UK, consultation rates within general practice have grown steadily since 1995 with an average of 5.5 consultations per person in 2008. ${ }^{2}$ The majority $(85 \%)$ of Canadians have a regular family physician, with $77 \%$ consulting a family physician per year. ${ }^{3}$
\end{abstract} risks, and receipt of patient-centred care.

\section{Design and setting}

Cross-sectional survey of patients attending Australian general practice clinics.

\section{Method}

Patients completed a touchscreen survey in the waiting room to rate the care received from their GP across eight domains of patientcentred care. Patients also completed the Patient Health Questionnaire (PHQ-9) and selfreported health risk factors. GPs completed a checklist for each patient asking about the presence of health risk factors.

\section{Results}

In total1486 patients and 51 GPs participated. Overall, $83 \%$ of patients perceived that the care they received was patient-centred across all eight domains. Patients most frequently perceived the access to health care when needed' domain as requiring improvement $(8.3 \%)$. Not having private health insurance and attending a practice located in a disadvantaged area were significantly associated with perceived need for improvements in care $(P<0.05)$.

\section{Conclusion}

Patients in general practice report that accessibility is an aspect of care that could be improved. Further investigation of how indicators of lower socioeconomic status interact with the provision of patient-centred care and health outcomes is required.

\section{Keywords}

general practice; patient care; primary health care; quality of health care.

\section{INTRODUCTION}

GPs are often a patient's first point of

\section{Challenges to the delivery of quality health care in general practice}

Given the breadth of their role, GPs must often manage competing priorities. ${ }^{4}$ Meeting patient expectations is complicated by resource and time constraints. ${ }^{5}$ As the population ages, the burden imposed by chronic diseases and associated risk factors, such as hazardous drinking, smoking, obesity, and physical inactivity, will increase. ${ }^{4}$ Coupled with the limited resources of the health system and variations in clinical practice, there is concern for the impact that these increased demands will have on the quality of care general practice patients receive. There

A Waller, BA Psych (Hons), PhD, post-doctoral research fellow; BM Carey, BSc (Hons), DPsych (Health), NHMRC TRIP fellow; A Grady, PhD candidate, BPsych; R Sanson-Fisher, BA Psych, ClinPsych, PhD, AO, director, Health Behaviour Research Group, Priority Research Centre for Health Behaviour, University of Newcastle, Callaghan, New South Wales, Australia. D Mazza, MD, FRACGP, DRANZCOG, Department of General Practice, School of Primary Health Care, Monash University, Victoria, Australia. S Yoong, BPsych, PhD, Population Health, Hunter New England Local Health District, Newcastle, New South Wales, Australia. is a need to measure the quality of health care delivered in general practice, to inform innovative approaches to meet competing demands while maintaining a high standard of care. ${ }^{6}$

\section{Consumer perspective of quality of care in general practice}

Various definitions and frameworks exist concerning quality in general practice.? The Institute of Medicine's seminal report Crossing the Quality Chasm ${ }^{8}$ set six indicators of quality health care, one of which is patient-centred care. Patient-centred care aims to arrange care consistent with patient preferences and values. ${ }^{8,9} \mathrm{It}$ is associated with increased adherence to treatment, improved communication and quality of life, and fewer unnecessary referrals. ${ }^{10-12}$ Relying solely on clinicians' estimates of care quality is problematic, as they may be incorrect in their assumptions of patients' views. ${ }^{10}$ Reporting bias is also likely to occur in these circumstances. Therefore, direct assessment of patient views regarding quality of care is an essential component of the evaluation of the quality of general practice care.

There have been several studies in Australia and overseas that have assessed patient satisfaction with care using measures such the General Practice Assessment Survey (GPAS) $)^{6,13,14}$; or General

\section{Address for correspondence}

Amy Waller, Health Behaviour Research Group, University of Newcastle, Callaghan, NSW 2308, Australia.

E-mail: Amy.Walleranewcastle.edu.au Submitted: 2 December 2014; Editor's response: 4 January 2015; final acceptance: 2 February 2015 (CBritish Journal of General Practice

This is the full-length article (published online 27 Apr 2015) of an abridged version published in print. Cite this article as: Br J Gen Pract 2015; DOI: 10.3399/bjgp15X684841 


\section{How this fits in}

Meeting patient expectations for care is complicated by the resource and time constraints faced by GPs. This study aimed to determine whether patients in general practice perceived the care they received as 'patient-centred'. Overall, patients were found to perceive their care as patientcentred; however, there are still challenges in relation to accessibility, especially in patients with lower socioeconomic status.

Practice Assessment Questionnaire (GPAQ). ${ }^{15,16}$ These measures focus on satisfaction with care across several domains. The GPAQ, for example, has six domains related to satisfaction with receptionists, practice nurses, access, communication, and the practice overall. ${ }^{15}$ These domains do not capture all of the areas of care that contribute to patientcentred care. Information about patient views across a broader range of domains of patient-centred care, ${ }^{17}$ as outlined by the Institute of Medicine, would provide a more comprehensive view of care quality.

\section{Influence of patient and practice characteristics on perceptions of "patient- centredness'}

Previous studies have found associations between patient demographic characteristics and access to care, patient-centeredness, and satisfaction. 13,18 Better health status, older age, higher education, and being female were associated with higher rated access and patient-centeredness of care. ${ }^{13,19}$ These studies also explored the relationship between practice characteristics (for example, location and number of GPs) and quality of care. ${ }^{13,18}$ However, they did not examine whether indicators of better technical care typically requiring more complex management, such as the provision of preventive care, are associated with highquality care. GPs play a key role in identifying and managing health risk behaviours Best practice preventive care requires regular assessment of these risk factors, and subsequent intervention. Discussion of preventive care requires excellent communication skills, and a whole-person approach to assessment and management. Hence, identification of lifestyle risk factors may be one aspect of technical care that is associated with a patient-centred approach. These data could help to focus quality improvement efforts on the aspects of care and those patients in most need.

Therefore, this study aimed to determine whether patients receiving care in a general practice setting perceive that the care they receive is 'patient-centred' across eight domains of care, and to identify associations between sociodemographic, GP and practice characteristics, detection of preventive health risks, and delivery of patient-centred care.

\section{METHOD}

\section{Design}

A large cross-sectional survey examining cardiovascular disease and cancer risk factors lincluding smoking, alcohol, hypertension, diabetes, and family historyl was undertaken with general practice patients attending 12 general practices in New South Wales and Victoria between September 2010 and November 2011.20-27 The sample included any person aged $\geq 18$ years attending the general practice during the study period. It was not restricted to people with cancer or cardiovascular disease.

\section{Participants and procedure}

The sample and recruitment procedures of the larger study have been described in detail previously. ${ }^{27}$ Briefly, practices in a defined geographical area were approached randomly until four from within an area each agreed to participate. Practices were eligible if two or more full-time equivalent GPs agreed to participate. Each participating GP was asked to complete a simple 1-page checklist for a consecutive subset of 35 of their participating patients. The survey assessed the GP's perceptions of each patient's health risk factors (smoking, obesity, clinical depression, risky alcohol consumption, and inadequate physical activity), and whether the patient was up to date with recommended cardiovascular disease and cancer screening. Only results relating to the five health risk factors (depression, smoking, alcohol, obesity, and physical activityl are presented here. The survey was provided to the GP immediately after patients completed their survey. GPs were asked to complete the survey any time within the session and could refer to their notes if they wished. The patient's name and date of birth was listed on the GP survey so that it could be linked to patient survey results.

Eligible patients attending consenting practices were aged $\geq 18$ years and had sufficient comprehension of English to complete the touchscreen computer survey. Patients who were attending the practice for the first time, or were too unwell or unable to give informed consent 
were excluded. Eligible patients were approached by a trained research assistant in the general practice clinic, provided with verbal and written information about the study and asked for consent to participate. Consenting patients completed a survey using a touchscreen computer in the waiting room before their consultation including demographic characteristics, health risk factors, screening behaviours, and perceptions of patient-centred care. Completion time was $\leq 15$ minutes for $89 \%$ of patients, with $58 \%$ of patients completing the survey in $<10$ minutes. ${ }^{25}$ Only results related to patient perceptions of quality of care are reported here.

\section{Outcome measures}

Quality of patient-centred care. A single item 'Please indicate the area(s) of your general practice care at [this clinic] that you would have liked improved?' was used to identify areas of care that participants felt required improvement. The eight areas of care were 'management of my physical symptoms', 'information and communication about my health care', 'emotional support', 'involvement of and support of my family/friends', 'being treated compassionately and with dignity', 'access to health care when needed', 'support to cope with my relationships', and 'assistance with practical concerns (for example, child care)'. Participants were asked to rank up to eight areas of care that they felt required improvement, in order of importance from 1 (most important) to 8 (least important). If participants felt that no improvements in any of the areas of care were required, they were instructed to select the option 'No improvements needed'. This measure has been used with oncology patients, and has adequate internal consistency $(\alpha=0.92) .{ }^{28}$

\section{Independent predictors}

Patient characteristics. Age, sex, number of GP visits, private health insurance status, health care card, highest level of education, and Aboriginal and/or Torres Strait Islander ethnicity.

Lifestyle health risk factors lpatient selfreported). Alcohol intake was determined using a modified version of the 3-item WHO Alcohol Use Disorder Identification Test. ${ }^{29}$ Participants were considered 'at risk' if they reported more than two standard drinks 2-3 times per week, or at least per week (lifetime risk); and/or if they had at least standard drinks on any occasion, daily, almost daily or weekly (risk on single occasion).

Smoking was measured by a single- item question in an Australian state-wide questionnaire. ${ }^{30}$ Current smokers were those reporting daily or occasional smoking.

Participants reported their weight and height without shoes. Body mass index (BMI) was calculated and overweight/obesity was defined as having a $\mathrm{BMI} \geq 25 \mathrm{~kg} / \mathrm{m}^{2}$.

A measurement of clinical depression was made using the Patient Health Questionnaire-9 (PHQ-9) to assess how often in the previous 2 weeks patients had been bothered by a number of depressionrelated symptoms. Participants were categorised as being depressed if they scored $\geq 10$ on this scale. ${ }^{31}$

Physical activity was assessed using the standard single-item 'As a rule, do you do at least half an hour of moderate or vigorous exercise on 5 or more days a week?'.32 Participants answering 'no/not sure' were classified as having insufficient levels of physical activity.

Detection of health risks (GP reported). GPs were asked whether their patients had any of five health risks (depression, smoking, alcohol, BMI, and physical activity). GPs could respond yes, no, or unsure to each health risk.

GP and practice variables. Age group, sex, number of sessions worked per week, and number of years in general practice were obtained for each GP. Data on bulk billing, availability of practice nurse, and practice postcode were also obtained for each practice.

\section{Statistical analysis}

Patient consenters and non-consenters were compared on sex using $\chi^{2}$ analyses to examine consent bias. Participants were defined as having endorsed an area of care in need of improvement if they chose to rank it between ' 1 ' (most important) and ' 8 ' (least important). The proportion of participants endorsing each area of care was reported with $95 \%$ confidence intervals (Cls). The proportion of patients ranking each area of care as the most important (that is, ranked '1') was also reported. Responders were then dichotomised on the basis of: 'No domains endorsed' versus 'Domain endorsed' (1 domain needing improvement). Generalised Estimating Equations were used to explore associations between explanatory variables and the dichotomised domain variable. The model used an exchangeable correlation matrix and adjusted for clustering by doctor. The explanatory patient variables were age group, sex, education, ethnic 


\begin{tabular}{|c|c|}
\hline Characteristic & $n(\%)$ \\
\hline \multicolumn{2}{|l|}{ Age, years } \\
\hline $18-29$ & $164(11)$ \\
\hline $30-39$ & $196(13)$ \\
\hline $40-49$ & $244(16)$ \\
\hline $50-59$ & $247(17)$ \\
\hline $60-69$ & 279 (19) \\
\hline$\geq 70$ & $356(24)$ \\
\hline \multicolumn{2}{|l|}{ Sex } \\
\hline Male & 581 (39) \\
\hline Female & $905(61)$ \\
\hline \multicolumn{2}{|l|}{ Education } \\
\hline High school and below & $616(42)$ \\
\hline TAFE/Dip & $210(14)$ \\
\hline University/tertiary & $454(31)$ \\
\hline Postgraduate & $102(7)$ \\
\hline Other & $45(3)$ \\
\hline Missing & $59(3)$ \\
\hline \multicolumn{2}{|l|}{ Chronic disease } \\
\hline None & 1089 (73) \\
\hline One to two chronic diseases & $382(26)$ \\
\hline Three or more chronic diseases & $15(1)$ \\
\hline Indigenous & $6(0.4)$ \\
\hline Private health insurance & $908(61)$ \\
\hline
\end{tabular}

background, private health insurance, and health status. As detection variables, patient self-reported lifestyle risk factors were compared with GP perceptions of health risk factors. The number of risk factors accurately detected by the GP (for example, both patient and GP indicated that the patient was a smokerl was included

\section{Table 2. Proportion of participants who perceived the need for improvement in each of the domains}

\begin{tabular}{|c|c|c|c|c|}
\hline Domain & $\begin{array}{l}\text { Identified as needing } \\
\text { improvement, } n(\%)^{\mathrm{a}}\end{array}$ & $95 \% \mathrm{Cl}$ & $\begin{array}{l}\text { Top ranked area for } \\
\text { improvement, } n(\%)^{\mathrm{b}}\end{array}$ & $95 \% \mathrm{Cl}$ \\
\hline $\begin{array}{l}\text { Management of my physical } \\
\text { symptoms }\end{array}$ & $59(4.0)$ & 3.0 to 5.0 & $36(2.4)$ & 1.6 to 3.2 \\
\hline $\begin{array}{l}\text { Information and communication } \\
\text { about my health care }\end{array}$ & $57(3.8)$ & 2.9 to 4.8 & $35(2.4)$ & 1.6 to 3.1 \\
\hline Emotional support & $59(4.0)$ & 3.0 to 5.0 & $33(2.2)$ & 1.5 to 3.0 \\
\hline $\begin{array}{l}\text { Involvement of and support of my } \\
\text { family/friends }\end{array}$ & $16(1.1)$ & 0.6 to 1.6 & $4(0.3)$ & 0.0 to 0.5 \\
\hline $\begin{array}{l}\text { Being treated compassionately and } \\
\text { with dignity }\end{array}$ & 48 (3.2) & 2.3 to 4.1 & $26(1.7)$ & 1.1 to 2.4 \\
\hline Access to health care when needed & 123 (8.3) & 6.9 to 9.7 & $95(6.4)$ & 5.1 to 7.6 \\
\hline $\begin{array}{l}\text { Support to cope with my } \\
\text { relationships }\end{array}$ & $19(1.3)$ & 0.7 to 1.9 & $8(0.5)$ & 0.2 to 0.9 \\
\hline $\begin{array}{l}\text { Assistance with practical concerns } \\
\text { (for example, child care) }\end{array}$ & $12(0.8)$ & 0.4 to 1.3 & $5(0.3)$ & 0.0 to 0.6 \\
\hline $\begin{array}{l}\text { No improvements in any domain } \\
\text { needed }\end{array}$ & $1235(83.1)$ & 81.2 to 85.0 & 1233 (83.0) & 81.1 to 84.9 \\
\hline
\end{tabular}

in the analysis as a percentage of the risk factors that the patient self-reported. GP and practice variables were age, sex, number of sessions worked per week and years in general practice, bulk billing, and practice Socio-Economic Indexes for Areas (SEIFA) deciles, 33 with higher scores indicating higher socioeconomic status. Analyses were conducted using SAS (version 9.4).

\section{RESULTS}

\section{Sample}

Forty-eight practices were approached to participate in the study, with 12 consenting (response rate $25 \%$ ). This study was part of a larger study where a total of 4079 eligible patients (86\%) and 53 GPs (63\%) consented to participate. There were no significant differences in the sex of consenters and non-consenters $(P>0.05)$. Of the 53 consenting GPs, 51 completed at least one survey for 1645 patients. Of these, 1486 patients indicated that they had visited the clinic at least once and were included in the analysis (Table 1).

\section{Proportion of patients endorsing domains} of patient-centred care

Overall, $83 \%$ of patients perceived that the care they received was 'patient-centred' across all domains (Table 2). In those who perceived that their care needed improvement in at least one domain (17\%), the domain perceived most frequently as needing improvement was access to health care when needed' (8.3\%). The domain perceived least frequently as needing improvement was assistance with practical concerns' (0.8\%).

\section{Characteristics associated with perceiving at least domain needing improvement}

Participants with private health insurance had lower odds of perceiving any domains needing improvement (OR 0.61, 95\% $\mathrm{Cl}=0.41$ to $0.91, P<0.05)$, compared with participants without private health insurance (Table 3). Participants who attended a practice located in a less disadvantaged area (that is, SEIFA score $\geq 7$ ) had lower odds of perceiving any domains needing improvement $\operatorname{lOR} 0.64,95 \% \mathrm{Cl}=0.46$ to $0.90, P<0.05)$, compared with participants attending a practice located in a more disadvantaged area.

\section{DISCUSSION}

\section{Summary}

Patient-centred care is care that "establishes a partnership among practitioners, patients, 
Table 3. Factors associated with patient perception of at least one domain in need of improvement

\begin{tabular}{|c|c|c|c|c|c|}
\hline \multirow[b]{2}{*}{ Characteristic } & \multicolumn{3}{|c|}{ Patient identified need for improvement } & \multicolumn{2}{|c|}{ Odds of at least one area endorsed } \\
\hline & $\begin{array}{c}\text { No areas of } \\
\text { improvement } \\
(n=1235), n(\%)\end{array}$ & $\begin{array}{c}\text { At least one area } \\
\text { of improvement } \\
(n=240), n(\%)\end{array}$ & $\begin{array}{c}\text { Crude } \\
P \text {-value }\end{array}$ & $\begin{array}{c}\text { Adjusted odds ratio } \\
\text { (95\% CI) }\end{array}$ & $P$-value ${ }^{a}$ \\
\hline \multicolumn{6}{|l|}{ Patient variables } \\
\hline \multicolumn{6}{|l|}{ Age, years } \\
\hline $18-29$ & 130 (79) & $34(21)$ & 0.002 & 1.00 (1.00 to 1.00$)$ & 0.449 \\
\hline $30-39$ & $158(81)$ & 37 (19) & & 0.91 (0.50 to 1.63 ) & \\
\hline $40-49$ & $193(79)$ & $50(21)$ & & 1.13 (0.62 to 2.05 ) & \\
\hline $50-59$ & $199(81)$ & $46(19)$ & & 0.78 (0.41 to 1.47 ) & \\
\hline $60-69$ & 246 (89) & $31(11)$ & & 0.58 (0.28 to 1.21$)$ & \\
\hline$\geq 70$ & $309(88)$ & $42(12)$ & & 0.70 (0.35 to 1.37$)$ & \\
\hline \multicolumn{6}{|l|}{ Sex } \\
\hline Male & $483(83)$ & $96(17)$ & 0.650 & 1.03 (0.79 to 1.34$)$ & 0.829 \\
\hline Female & 752 (84) & $144(16)$ & & 1.00 (1.00 to 1.00$)$ & \\
\hline \multicolumn{6}{|l|}{ Education } \\
\hline High school and below & $529(86)$ & $87(14)$ & 0.193 & 1.00 (1.00 to 1.00 ) & 0.196 \\
\hline TAFE/Dip & $166(79)$ & $44(21)$ & & 1.43 (0.84 to 2.43 ) & \\
\hline University/tertiary & $382(84)$ & $72(16)$ & & 1.45 (0.96 to 2.19 ) & \\
\hline Postgraduate & 80 (78) & $22(22)$ & & 2.55 (1.29 to 5.07 ) & \\
\hline Other & 37 (82) & $8(18)$ & & 1.42 (0.55 to 3.65$)$ & \\
\hline \multicolumn{6}{|l|}{ Chronic disease } \\
\hline None & $907(84)$ & $175(16)$ & 0.971 & 0.99 (0.69 to 1.44$)$ & 0.468 \\
\hline One to two diseases & 316 (83) & $63(17)$ & & 1.00 (1.00 to 1.00$)$ & \\
\hline Three or more diseases & $12(86)$ & $2(14)$ & & 0.44 (0.08 to 2.51) & \\
\hline \multicolumn{6}{|l|}{ Indigenous status } \\
\hline Indigenous & $4(67)$ & $2(33)$ & 0.188 & 1.00 (1.00 to 1.00$)$ & 0.298 \\
\hline Non-indigenous & $1231(84)$ & $238(16)$ & & 0.37 (0.10 to 1.36 ) & \\
\hline \multicolumn{6}{|l|}{ Private health insurance } \\
\hline Yes & $783(86)$ & $125(14)$ & 0.003 & 0.61 (0.41 to 0.91 ) & 0.030 \\
\hline No & $452(80)$ & $115(20)$ & & 1.00 (1.00 to 1.00 ) & \\
\hline \multicolumn{6}{|l|}{$\begin{array}{l}\text { Detection health risk } \\
\text { factors, } \%\end{array}$} \\
\hline$\leq 40$ & $610(85)$ & $111(15)$ & 0.044 & 1.00 (1.00 to 1.00$)$ & 0.182 \\
\hline $41-80$ & $256(79)$ & $68(21)$ & & 1.43 (1.00 to 2.04$)$ & \\
\hline$>80$ & $232(84)$ & $45(16)$ & & $1.12(0.75$ to 1.68$)$ & \\
\hline \multicolumn{6}{|l|}{ GP and practice variables } \\
\hline \multicolumn{6}{|l|}{ GP sex } \\
\hline Male & 845 (84) & $165(16)$ & 0.933 & $1.09(0.74$ to 1.61$)$ & 0.660 \\
\hline Female & 390 (84) & $75(16)$ & & 1.00 (1.00 to 1.00$)$ & \\
\hline \multicolumn{6}{|l|}{ GP age, years } \\
\hline $25-44$ & 343 (85) & $62(15)$ & 0.704 & 1.00 (1.00 to 1.00$)$ & 0.928 \\
\hline $45-54$ & $434(83)$ & $92(17)$ & & 0.96 (0.60 to 1.51 ) & \\
\hline$\geq 55$ & $458(84)$ & $86(16)$ & & 0.91 (0.55 to 1.50 ) & \\
\hline \multicolumn{6}{|l|}{ GP experience, years } \\
\hline$\leq 5$ & 1203 (84) & $234(16)$ & 0.992 & 3.40 (0.63 to 18.23$)$ & 0.217 \\
\hline $6-19$ & $11(85)$ & $2(15)$ & & 1.14 (0.13 to 9.72 ) & \\
\hline$\geq 20$ & $21(84)$ & $4(16)$ & & 1.00 (1.00 to 1.00$)$ & \\
\hline \multicolumn{6}{|l|}{ Sessions per week, $n$} \\
\hline$\leq 5$ & $1211(84)$ & $233(16)$ & 0.363 & 1.00 (1.00 to 1.00$)$ & 0.140 \\
\hline$\geq 6$ & $24(77)$ & $7(23)$ & & $3.45(0.81$ to 14.71$)$ & \\
\hline \multicolumn{6}{|l|}{ Bulk bill } \\
\hline 2 & $514(87)$ & 76 (13) & 0.021 & 1.00 (1.00 to 1.00$)$ & 0.114 \\
\hline 2,3 & $128(85)$ & $23(15)$ & & 1.21 (0.73 to 2.00 ) & \\
\hline 3 & $504(81)$ & $122(19)$ & & 1.57 (1.04 to 2.36$)$ & \\
\hline \multicolumn{6}{|l|}{ SEIFA score } \\
\hline$\leq 6$ (low SES) & $292(78)$ & $82(22)$ & $<0.001$ & 1.00 (1.00 to 1.00$)$ & 0.037 \\
\hline$\geq 7$ (high SES) & $942(86)$ & $158(14)$ & & 0.64 (0.46 to 0.90 ) & \\
\hline
\end{tabular}

and their families to ensure that decisions are respectful of, and responsive to, the patients' preferences, needs and values of patients'. ${ }^{34}$ Patient-centred care leads to improvements in the quality and safety of health care, provider satisfaction, and patient care experience, as well as reduced costs. Eliciting patient views about the quality of care they receive can help to identify potential inequities in primary care, and inform targeted quality improvement activities.

\section{Strengths and limitations}

This is one of few, large-scale Australian studies exploring general practice patient perceptions of patient-centred care. The characteristics of participants are comparable with those reported in the Bettering the Evaluation and Care of Health (BEACH) study, ${ }^{35}$ suggesting that these findings are generalisable among the wider community of Australian GPs and patients. The high consent and survey completion rates support the feasibility and acceptability of collecting data from patients while they wait for appointments, and the potential for incorporating into routine clinical practice. ${ }^{25}$ Participating practices were confined to urban areas, so it is not clear how generalisable these results may be to rural and remote areas of Australia where issues related to lower access to bulk billing services, and higher GP:patient ratios may influence patient perceptions. ${ }^{36,37}$ It is also unclear how generalisable the present results are to other countries given differences in access and funding. The study relied on patient and GP self-report. Although self-report data may be susceptible to social desirability bias, they have been shown to be reliable, particularly when assessing demographics and health risks. ${ }^{26,38,39}$

The low proportion of patients endorsing individual domains of patient-centred care as needing improvement in the present study meant that it was not possible to explore the characteristics that were associated with specific domains. The amount of information provided to patients about what each domain referred to was limited, which may have influenced patient responses. Also, the proportion of patients who had concerns that needed assistance within each of the domain areas is not known. For example, few people reported the need for improvements in the domain 'assistance with practical concerns'. The measure does not distinguish whether this rating was a consequence of few patients having practical concerns, or 
the care provided was already patientcentred. Further work is needed to clarify which patients are experiencing unmet needs in the domain areas as well as their perceptions that their care needs improvement, to better target improvement strategies. The specific barriers to achieving patient-centred care in domains identified as requiring improvement also need further clarification.

\section{Comparison with existing literature}

Previous research reports high levels of patient satisfaction with continuity of care, nursing care, and communication. ${ }^{16}$ It is encouraging that the vast majority of general practice patients in the present study also perceived that their care was patient-centred. The domain that was most in need of improvement was access to care when needed'. Previous studies have also reported lowest satisfaction with being able to access care when needed. ${ }^{16}$ Poor access to GP care may occur for a variety of reasons, including a shortage of providers, increased waiting times, or lack of continuity. Poor access to GP care has significant implications for the healthcare system. For example, $25 \%$ of Australian patients who visited an emergency department perceived that this care could have been provided by a GP.40 Similar data have been reported in the UK and US. ${ }^{41-43}$ Developing effective strategies to promote access to GP care, therefore, has important implications for improving the management of chronic diseases, as well as reducing unnecessary emergency department use. One example is the UK's Quality and Outcomes Framework, which provides financial incentives for general practices reviewing patient access and the impact on emergency department use.41 However, evidence of the effectiveness of this programme has yet to be confirmed. ${ }^{41}$

Indicators of lower socioeconomic status (SES), such as not having private health insurance and attending a practice located in a disadvantaged area, were associated with a greater perceived need for improved care. Previous findings on the impact of SES on patient perceptions of quality of care are mixed. One UK study of patients from over 8000 practices found that SES only has small and inconsistent associations with patient satisfaction. ${ }^{44}$ Another UK study found that patients in more deprived areas had lower access and less satisfaction with care. ${ }^{45}$ This has been attributed to the inverse care law', whereby availability of health care tends to be inversely related to the need for it in the population served. ${ }^{46}$ This interpretation of a negative relationship between SES and satisfaction with care may be applicable to Australia. Although not assessed in the current study, previous studies have indicated that despite patients with low SES having more health problems, they receive fewer long (>20 minutes) consultations than those in advantaged areas. ${ }^{47}$ These factors may account for differences in the perceptions of care between patients with high and low SES.

Previous studies have reported associations between patient-related and practice-related factors and patientcentredness. A previous study of primary care patients with a chronic disease found that those who were older, female, reported better health, and were from urban areas rated their care as more patient-centred. ${ }^{13}$ In contrast to the present findings, those who were employed and well educated were less satisfied with access to care and patient-centredness of care than other patients. ${ }^{13}$ All patients in the study had a chronic disease, which may have contributed to the discrepancies. ${ }^{13}$ Where healthcare needs are similar, it may be that higher SES patients' have higher expectations of care, resulting in poorer ratings of care.

Direct comparisons between the present findings and these previous studies are problematic, given their use of alternative, longer tools, such as the GPAS. Items used to measure the quality of patient-centred care in the current study were adapted from a tool used in radiation oncology outpatients. ${ }^{28}$ The tool gives a quick snapshot of the domains that patients may perceive as needing improvement, using only a single item to assess each domain. Although the measure appears to have both face validity and internal reliability, ${ }_{1}^{28}$ the psychometric properties require further testing in general practice.

\section{Implications for research and practice}

Eighty-three per cent of responders perceived that the care they received was patient-centred across the eight domains of care. Access to care was the domain most commonly identified as needing improvement. Not having private health insurance and attending a practice located in a disadvantaged area were associated with perceiving a greater need for improvement in care. Further investigation of how these factors interact with the provision of patient-centred care and health outcomes of patients is required. 


\section{REFERENCES}

1. Australian Institute of Health and Welfare. General practice activity in Australia 2009-10. Canberra: AlHW, 2010

2. The Health and Social Care Information Centre. Trends in consultation rates in general practice 1995 to 2008: analysis of the QResearch database. Leeds: NHS, 2009.

3. Canadian Institute of Health Information. Health care in Canada, 2012: a focus on wait times. Ottawa: $\mathrm{ClHI}, 2012$.

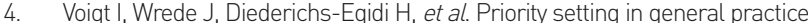
health priorities of older patients differ from treatment priorities of their physicians. Croat Med J 2010; 51(6): 483-492.

5. Cheraghi-Sohi S, Hole AR, Mead N, et al. What patients want from primary care consultations: a discrete choice experiment to identify patients' priorities. Ann Fam Med 2008; 6(2): 107-115.

6. Campbell SM, Roland MO, Buetow SA. Defining quality of care. Soc Sci Med 2000: 51(11): 1611-1625.

7. Gardner K, Mazza D. Quality in general practice - definitions and frameworks Aust Fam Physician 2012; 41(3): 151-154

8. Institute of Medicine. Crossing the quality chasm: a new health system for the 21st century. Washington, DC: National Academy Press, 2001.

9. Australian Commission on Safety and Quality in Health Care. Patient-centred care: improving quality and safety by focusing on patients ad consumers. Canberra: ACSQHC, 2010.

10. Stewart M, Ryan BL, Bodea C. Is patient-centred care associated with lower diagnostic costs? Health Policy 2011; 6(4): 27-31

11. Kinmonth AL, Woodcock A, Griffin S, et al. Randomised controlled trial of patient centred care of diabetes in general practice: impact on current wellbeing and future disease risk. The Diabetes Care From Diagnosis Research Team. BMJ 1998; 317(7167): 1202-1208

12. Bauman AE, Fardy HJ, Harris PG. Getting it right: why bother with patientcentred care? Med J Aust 2003; 179(5): 253-256.

13. Jayasinghe UW, Proudfoot J, Holton C, et al. Chronically ill Australians satisfaction with accessibility and patient-centredness. Int J Qual Health Care 2008; 20(2): 105-114

14. Ramsay J, Campbell JL, Schroter S, et al. The General Practice Assessment Survey (GPAS): tests of data quality and measurement properties. Fam Pract 2000; 17(5): 372-379.

15. Mead N, Bower P, Roland M. The General Practice Assessment Questionnaire (GPAQ] - development and psychometric characteristics. BMC Fam Pract 2008; 9: 13

16. Potiriadis M, Chondros $\mathrm{P}$, Gilchrist $\mathrm{G}$, et al. How do Australian patients rate their general practitioner? A descriptive study using the General Practice Assessment Questionnaire. Med J Aust 2008; 189(4): 215-219.

17. Hudon C, Fortin M, Haggerty J, et al. Patient-centered care in chronic disease management: a thematic analysis of the literature in family medicine. Patient Educ Couns 2012; 88(2): 170-176.

18. Jayasinghe UW, Proudfoot J, Barton CA, et al. Quality of life of Australian chronically-ill adults: patient and practice characteristics matter. Health Qual Life Outcomes 2009; 7: 50

19. Mead N, Roland M. Understanding why some ethnic minority patients evaluate medical care more negatively than white patients: a cross sectional analysis of a routine patient survey in English general practices. BMJ 2009; 339: b3450.

20. Carey M, Bryant J, Yoong SL, et al. Prostate specific antigen testing in family practice: a cross sectional survey of self-reported rates of and reasons for testing participation and risk disclosure. BMC Fam Pract 2013; 14: 186.

21. Carey $M$, Jones $K$, Meadows $G$, et al. Accuracy of general practitioner unassisted detection of depression. Aust N Z J Psychiatry 2014; 48(6): 571-578.

22. Carey M, Jones KA, Yoong SL, et al. Comparison of a single self-assessment item with the PHQ-9 for detecting depression in general practice. Fam Pract 2014; pii: cmu018. [Epub ahead of print]

23. Carey M, Small H, Yoong SL, et al. Prevalence of comorbid depression and obesity in general practice: a cross-sectional survey. Br J Gen Pract 2014; DOI: 10.3399/bjgp14X677482
24. Paul C, Yoong SL, Sanson-Fisher R, et al. Under the radar: a cross-sectional study of the challenge of identifying at-risk alcohol consumption in the general practice setting. BMC Fam Pract 2014; 15: 74

25. Paul CL, Carey M, Yoong SL, et al. Access to chronic disease care in general practice: the acceptability of implementing systematic waiting-room screening using computer-based patient-reported risk status. Br J Gen Pract 2013; DOI: 10.3399/bjgp13X671605

26. Yoong SL, Carey ML, D’Este C, Sanson-Fisher RW. Agreement between selfreported and measured weight and height collected in general practice patients: a prospective study. BMC Med Res Methodol 2013; 13: 38.

27. Yoong SL, Carey ML, Sanson-Fisher RW, et al. Touch screen computer health assessment in Australian general practice patients: a cross-sectional study protocol. BMJ Open 2012; 2(4): e001405.

28. Mackenzie LJ, Sanson-Fisher RW, Carey ML, D’Este CA. Radiation oncology outpatient perceptions of patient-centred care: a cross-sectional survey. BMJ Open 2013; 3(2)

29. Bradley KA, DeBenedetti AF, Volk RJ, et al. AUDIT-C as a brief screen for alcohol misuse in primary care. Alcohol Clin Exp Res 2007; 31(7): 1208-1217.

30. Williamson M, Baker D, Jorm L. The NSW health survey program: overview and methods 1996-2000. NSW Public Health Bulletin 2001; 12: 1-3.

31. Kroenke K, Spitzer RL, Williams JB. The PHQ-9: validity of a brief depression severity measure. J Gen Intern Med 2001; 16(9): 606-613.

32. Rose SB, Elley CR, Lawton BA, Dowell AC. A single question reliably identifies physically inactive women in primary care. N Z Med J 2008; 121(1268): U2897.

33. Pink B. Socio-economic indexes for areas (SEIFA), technical paper. ABS Catalogue no. 2033.0.55.001. Canberra: ABS, 2011.

34. Institute of Medicine. Committee on Quality of Health Care in America. Crossing the quality chasm: a new health system for the 21st century. Washington, DC: National Academies Press; 2001

35. Britt HC, Miller GC. The Bettering the Evaluation and Care of Health (BEACH) program: where to from here? Med J Aust 2013; 198(3): 125-126.

36. General Practice Strategy Review Group. General practice: changing the future through partnerships. Canberra: Department of Health and Family Services, 1998

37. Griggs D, Atkin C. The bulk billing crisis: a Victorian perspective. VCOSS Melbourne, 2004.

38. Prince SA, Adamo KB, Hamel ME, et al. A comparison of direct versus selfreport measures for assessing physical activity in adults: a systematic review. Int $J$ Behav Nutr Phys Act 2008; 5: 56

39. Gorber SC, Tremblay MS. The bias in self-reported obesity from 1976 to 2005: a Canada-US comparison. Obesity 2010; 18(2): 354-361.

40. Australian Bureau of Statistics. Health services: use and patient experience. Canberra: ABS, 2011

41. Cowling TE, Cecil EV, Soljak MA, et al. Access to primary care and visits to emergency departments in England: a cross-sectional, population-based study. PLoS One 2013; 8(6): e66699.

42. Rust $G, Y e J$, Baltrus $P$, et al. Practical barriers to timely primary care access: impact on adult use of emergency department services. Arch Intern Med 2008; 168(15): 1705-1710.

43. Harris MJ, Patel B, Bowen S. Primary care access and its relationship with emergency department utilisation: an observational, cross-sectional, ecological study. Br J Gen Pract 2011; DOI: 10.3399/bjgp11X613124

44. Lyratzopoulos G, Elliott M, Barbiere JM, et al. Understanding ethnic and other socio-demographic differences in patient experience of primary care: evidence from the English General Practice Patient Survey. BMJ Qual Saf2012; 21(1): $21-29$.

45. Mercer SW, Watt GC. The inverse care law: clinical primary care encounters in deprived and affluent areas of Scotland. Ann Fam Med 2007; 5(6): 503-510.

46. Mercer SW, Guthrie B, Furler J, et al. Multimorbidity and the inverse care law in primary care. BMJ 2012; 344: e4152.

47. Furler JS, Harris $E$, Chondros $P$, et al. The inverse care law revisited: impact of disadvantaged location on accessing longer GP consultation times. Med J Aust 2002; 177(2): 80-83. 